makes the method more complicated and troublesome than a fusion with potassium nitrate and borax.

This was to be expected, since even chromic salts in solution require more than one treatment with sodium peroxide before complete oxidation to chromic acid is effected.

With this exception sodium peroxide has proved a very useful and convenient reagent, applicable in a great number and variety of cases. It ought to be, and no doubt will become, one of the standard reagents of a modern laboratory.

BALTIMORE, DECEMBER 7,7897 .

\title{
ADDITIONAL NOTES ON THE SUGAR-CANE AMID.
}

BY EDMUND C. SHOREY, Received January 8,1898 .

IN a paper on the principal amid of sugar-cane, which appeared in this Journal, November, I 897 , I gave the result of work done during the last grinding season on the amid present in sugar-cane. Since then I have been able to correct some errors in the work done then, and have also obtained additional proof of the correctness of the conclusion reached that this amid is amidoacetic acid and not asparagin.

The chief error in my former work which I wish to correct now, was with respect to water of crystallization. In the first examination of the crystallized sugar-cane amid it was found that the crystals, when well dried by pressing between filterpaper, did not lose weight during a short exposure to a temperature of $100^{\circ} \mathrm{C}$. Subsequently it was found that the crystals, when finely powdered, lost water at $105^{\circ}-110^{\circ} \mathrm{C}$, and the average of several determinations, drying until there was no further loss in weight, gave 10.72 per cent. This, if we accept the formula $\mathrm{CH}_{2} \mathrm{NH}_{2} \mathrm{COOH}$ as representing the molecule of glycocoll, is equivalent to half a molecule of water of crystallization. This was discovered too late to correct the error in my first paper.

The samples in which nitrogen was determined were in all cases finely powdered and dried at $110^{\circ} \mathrm{C}$. so that 18.69 , the per cent. of nitrogen stated, is that present in the amid after water of crystallization has been driven off.

The presence of water of crystallization in the sugar-cane amid of course invalidates my statement that it contains the 
same amount of nitrogen as asparagin: asparagin with one molecule of water of crystallization containing i 8.66 per cent., while the sugar-cane amid with half a molecule contains 16.6 per cent. nitrogen. I have recently made some determinations of the nitrogen in this amid, taking large clear crystals and drying merely by pressure between filter-paper. The average of four such determinations was 16.58 per cent. nitrogen.

In concentrating the filtrate from mercuric sulphide there is sometimes deposited, before crystallization of the amid takes place, a small quantity of white powder. This, on separation and examination under the microscope, presented the appearance of leucine, and when heated on platinum foil with nitric acid and then with caustic soda the yellow color and oily drop characteristic of this body were obtained. Leucine is not precipitated by mercuric nitrate and its presence no doubt has been due to some mercurous nitrate in the nitrate used. Spherules of leucine are apt to become incorporated in the crystals of glycocoll and may accompany it through several crystallizations, rendering nitrogen determinations, etc., inaccurate.

The evolution of hydrocyanic acid, on acidifying with hydrochloric acid after first heating with strong caustic potash, does not seem to be as satisfactory a reaction for glycocoll as at first appeared. In some instances I have obtained this reaction perfectly, and again on portions of the same sample it has failed. It seems to depend on the strength of the alkali and length of time of heating, and also on other conditions which I do not yet understand.

In the case of four samples of the sugar-cane amid I have distilled a known weight with a known excess of alkali, and received the distillate in successive portions of one cc. tenthnormal sulphuric acid, and measured each distillate. The actual figures obtained in one instance will best show what is to be learned from this.

0.2227 gram sugar-cane amid was distilled with 150 cc. water containing $0.377^{\circ}$ gram sodium hydroxide. The distillate was received into successive portions of one cc. tenth-normal sulphuric acid, the receiver being changed as soon as one cc. of acid was neutralized; litmus was used as indicator. 
The volume of first distillate was $36.0 \mathrm{cc}$.

\begin{tabular}{|c|c|c|c|c|c|}
\hline " & “ & "second & ، & "، & I 8.2 \\
\hline ، & “6 & "third & $" ،$ & $"$ & I 4.5 \\
\hline ، & “، & "fourth & " & $\because$ & 14.3 \\
\hline “ & “" & " fifth & ، & “ & I 3.5 \\
\hline ، & ، & " sixth & “ & $\because$ & 12.3 \\
\hline " & 16 & "seventh & s & "6 & I 2.3 \\
\hline "، & 36 & " eighth & ‘ & “6 & I 2.3 \\
\hline ، & “ & " ninth & « & $" ،$ & 8.5 \\
\hline
\end{tabular}

At this stage fifty cc. water containing 0.3770 gram sodium hydroxide were added and distillation continued.

The volume of tenth distillate was $7.5 \mathrm{cc}$.

" 30 "

with only one-tenth cc. acid neutralized. As the distillation had been carried nearly to dryness and the evolution of ammonia very slight, the distillation was stopped. The total nitrogen set free as ammonia was 0.0169 gram, $7.5^{8}$ per cent. or less than half that contained in the sample taken. This has been the general result obtained in other cases. The ammonia given off was small in amount until the alkali became concentrated, when the evolution was quite rapid, and approximately only half of the nitrogen was given off as ammonia, even when the distillation was carried nearly to dryness. The residue from the distillation with caustic soda was yellow in color, and, on being neutralized with hydrochloric acid, gave a jelly-like mass with brown flocks through it, and having the smell which is characteristic of the treatment of glue or fresh bones with alkali. This mass, when acidified with hydrochloric acid, gave off a small amount of hydrocyanic acid and resolved itself into a light brown solution with darker insoluble flocks floating through it. On filtering, neutralizing with anmonia, heating to boiling, and adding calcium chloride, a white precipitate was obtained presenting the characteristic microscopic appearance of calcium oxalate.

In view of the accepted formula for glycocoll, $\mathrm{CH}_{2} \mathrm{NH}_{2} \mathrm{COOH}$, that is, a molecule containing only one atom of nitrogen, its behavior when heated with alkali is somewhat puzzling. We 
must conclude either that the alkali attacks some molecules and not others, or different molecules in a different manner, or that the formula given above is not correct. It has been suggested that this formula should be doubled, giving a molecule containing two atoms of nitrogen, but a determination of the molecular weight by Raoult's method has not confirmed this. At any rate, whatever the formula and whatever the reactions when heated with alkali, it is clear from the number and character of the decomposition products, ammonia, hydrocyanic acid, oxalic acid, and the brown insoluble matter, that the reactions are by no means simple.

A much more satisfactory and conclusive test for the character of the sugar-cane amid I have found in the formation of hippuric acid from it and benzoic acid. The method of forming hippuric acid from these two bodies noticed in my first paper is one that requires heating to $160^{\circ} \mathrm{C}$. in a sealed tube for ten or twelve hours. A much simpler and convenient method is by the action of benzoyl chloride on the amid. A watery solution of the amid is made slightly alkaline with caustic soda and benzoyl chloride added drop by drop, with constant shaking, until an excess has been added, and then made strongly alkaline with caustic soda. On cooling hydrochloric acid is added to strong acidity, when hippuric acid and the excess of benzoic acid are precipitated. These two acids are removed by filtration, separated by petroleum ether, and the hippuric acid crystallized from water. If the solution is dilute the hippuric acid will not be completely thrown down by hydrochloric acid for some hours, but if sufficient time be given the yield of hippuric acid is very nearly theoretical. If a mere qualitative test is wanted, hippuric acid can be obtained from the sugar-cane amid by this method in ten minutes. The hippuric acid so obtained has been identified by the microscopic appearance of the crystals; its sparing solubility in cold water, insolubility in petroleum ether, and solubility in acetic ether; also its behavior when heated and per cent. of nitrogen-seven and eight-tenths contained. I have obtained hippuric acid from horses' urine, and after purification it is not distinguishable by any test, physical or chemical, from that obtained from the sugar-cane amid.

The formation, then, of hippuric acid from the sugar-cane 
amid is, I think, absolute proof that this anid is identical in constitution with glycocoll, i. e., amidoacetic acid. The ease with which the production of hippuric acid is brought about by the action of benzoyl chloride on the amid according to the equation

$\mathrm{C}_{6} \mathrm{H}_{5} \mathrm{COCl}+\mathrm{CH}_{2} \mathrm{NH}_{2} \mathrm{COOH}=\mathrm{C}_{6} \mathrm{H}_{6} \mathrm{CONHCOOH}+\mathrm{HCl}$, the purity of the hippuric acid obtained, and the ease with which it is separated, promise, I think, a simple and reliable method of estimating this amid in sugar-cane and its products.

I.ABORATORY OF KoHala SUGar Co., Kohala, Hawait, H. I.

\section{CORRESPONDENCE.}

DECEMBER 27,1897 .

To the Editor of the Journal of the American Chemical Society:

DEAR SIR: The great success of the Second International Congress of Applied Chemistry leads to the belief that the next one, which is to be held in Vienna in July, 1898 , will also be numerously attended. Nearly 2,000 members were present at the Paris meeting, and it required five large volumes to contain the report of its proceedings.

The undersigned have been appointed a committee in the United States, to promote the interests of the Third International Congress of Applied Chemistry, and beg leave to call the attention of the chemists of this country to that meeting, with the hope that many may be induced to attend. Those who subscribe and receive their membership cards will be entitled to all reductions in rates going to and coming from Vienna, which are arranged for members of the Congress. During the Paris meeting, the French line of steamers reduced its rates thirty-three per cent. to members of the Congress. It is hoped that an arrangement can be made with some of the steamship lines during the coming summer for a similar reduction, although the committee has not yet been informed of any arrangement of this kind.

The opportunity of meeting distinguished chemists from all parts of the world should not be lost sight of, and will doubtless be appreciated by the American members. The scientific work of the Congress will be divided into the following sections : 